\title{
Study on hydraulic resistance of erodible bed at the Chiyoda experimental flume
}

\author{
T. Kakinuma ${ }^{1}$, T. Inoue ${ }^{1}$, R. Akahori ${ }^{1, *}$, and A. Takeda ${ }^{2}$ \\ ${ }^{1}$ Civil Engineering Research Institute for Cold Region, Sapporo, Japan \\ ${ }^{2}$ Hokkaido Development Bureau, Obihiro, Japan \\ *now at: Aichi Institute of Technology, Toyota, Japan
}

Correspondence to: T. Kakinuma (kakinuma-t22aa@ceri.go.jp)

Received: 15 October 2013 - Revised: 4 March 2014 - Accepted: 16 March 2014 - Published: 1 April 2014

\begin{abstract}
The authors made erodible bed experiments under steady flow condition at the Chiyoda Experimental Flume, a large-scale facility constructed on the floodplain of the Tokachi River, and observed sand waves on the bed of the flume. In this study, the characteristics of the sand waves are examined along the longitudinal survey lines and confirmed to be dunes. Next, the authors estimated Manning's roughness coefficients from the observed hydraulic values and assumed that the rise of the coefficients attributed to the sand wave development. Finally, vertical flow distribution on the sand waves are examined, and observed velocity distribution on the crest of waves found to be explained by the logarithmic distribution theory.
\end{abstract}

\section{Introduction}

The riverbed configuration, that is in accordance with the hydraulic conditions (e.g., water depth, flow velocity, channel width) and the bed materials, is known to affect hydraulic resistance. Numerous studies have addressed the prediction of hydraulic resistance. Most such studies have addressed form drag on a riverbed with small scale sand waves and friction drag of the riverbed surface, and prediction of the total drag (i.e., form drag and friction drag combined).

In analysing the hydraulic resistance of erodible bed, Engelund (1966) introduced assumption of the general similarity of the dune formations, in which the ratio of the total energy loss and the expansion loss caused by dunes are same in the same Froude number condition, and he indicated that in flows with a similar riverbed configuration, the effective shear stress (friction drag) is an exclusive function of the to- tal shear stress (total drag). Kishi and Kuroki (1973) further studied the concept of Engelund and made the modification that the effective shear stress is a function of the total shear stress and the ratio of hydraulic radius to grain size. Yalin and Karahan (1979) and Kikkawa and Ishikawa (2011) estimated form drag by using riverbed (sand waves) form. Miwa and Daido (1991) proposed a hydraulic resistance estimation formula that incorporates a formula for calculating the parameters of sand wave form into the method proposed by Yalin.

Gilbert and Guy, Simons and Richardson made experiments on small scale sand waves. Their experiments confirmed that differences in bed slope, water depth and grain size produce various riverbed configurations, e.g., dunes, transition beds, flat beds and antidunes (Task Committee, 1973). Since then, experimental studies have actively addressed the sand wave deformation process, owing to the development of new technologies, such as those for measuring movable beds and analyzing images. Nakagawa and Tsujimoto (1976) made continuous measurements of the small scale sand wave formation process using an ultrasound riverbed measurement device, and they clarified that the wave height and the wave length both increase in accordance with sand wave development. In addition, Suzuki and Michiue (1991), and Miwa and Daido (1979) measured the sand waves that developed on riverbeds of mixed sand and clarified that mixed sand has less development than uniform sand, and that fine grains accumulate on the top of the sand waves crests.

In addition to these studies, there are many conventional experimental studies on small scale sand wave development and increases in hydraulic resistance. However, few studies have addressed the relationship between hydraulic resistance 

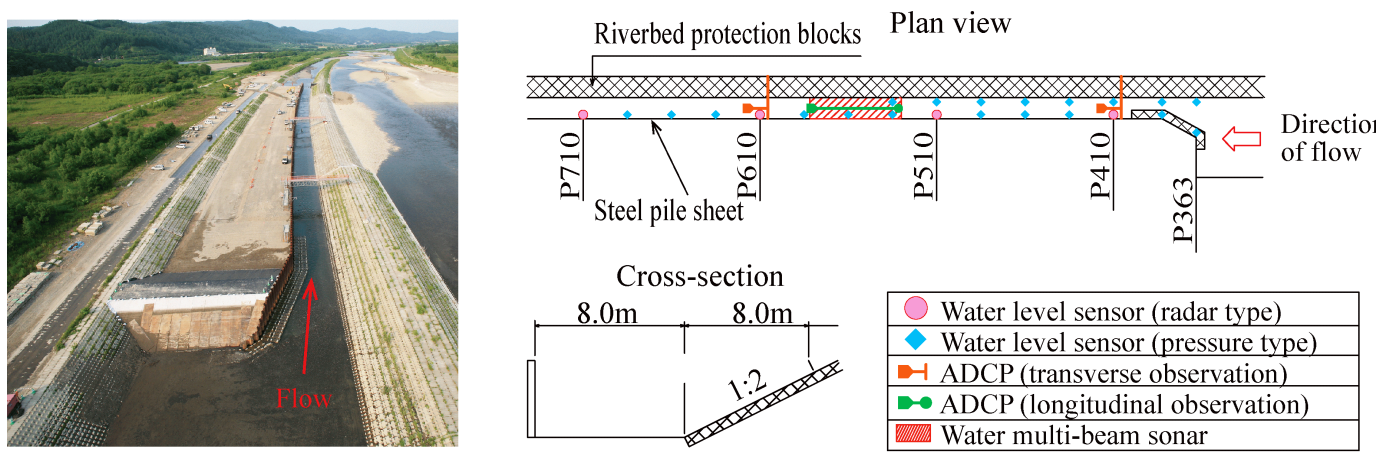

Fig. 1. View of experiment flume and hydraulic observation position.

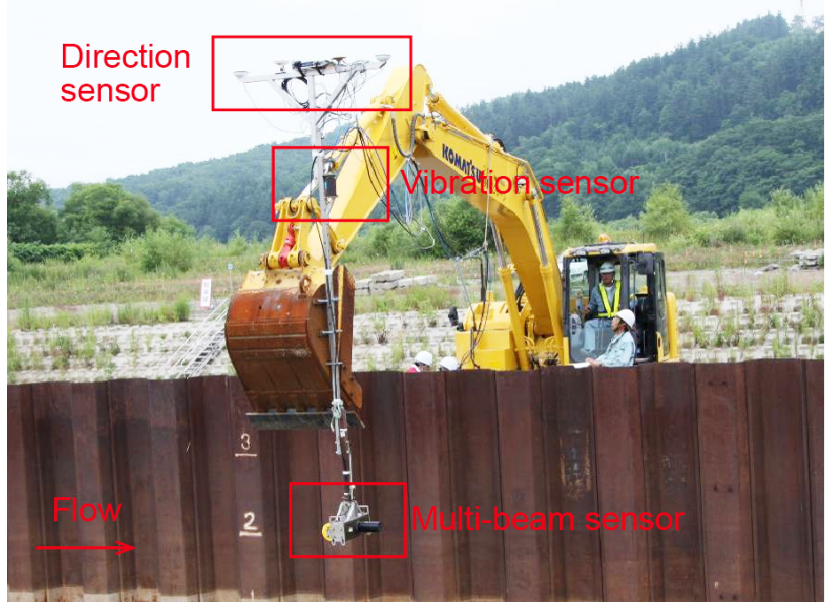

Fig. 2. Photo of sensors to observe sand waves.

and small scale sand waves by analyzing hydraulic data or riverbed observation data (Takemoto et al., 1982) from actual rivers. This is because it is difficult to take accurate, detailed measurements of bed form during floods.

The purpose of this study is to observe real scale sand waves and clarify characteristics of these sand waves, to estimate hydraulic resistance of the flume, and to clarify the applicability of the logarithmic theories of vertical flow distributions on sand waves.

\section{Experimental outline}

The experiment was made using part of the Chiyoda Experimental Flume (Fig. 1). The flume was built on the floodplain of the Tokachi River. With a maximum length of $1300 \mathrm{~m}$ and a maximum width of $30 \mathrm{~m}$, it is one of Japan's largest experimental flumes (Shimada et al,. 2011).

The configuration of the experimental flume and the locations of the measurement devices are also shown in Fig. 1. In this figure, measurement site locations are indicated with "P" and the three numerals following "P". The three numer- als give the distance $(\mathrm{m})$ between the inflow gate and the measurement site in the flow direction. Pile sheets were installed for bank protection on the left bank of the experimental flume, and concrete armour blocks were installed on the right bank slope. The initial riverbed was a flat bed with a slope of about 1/500.

During the test, the inflow discharge was regulated by the gate. The discharge was increased gradually for the first 90 min after the start of the test, was kept at a constant amount for about $6 \mathrm{~h}$, and was decreased to stop the inflow in 30 minutes. The target amount of inflow rate for Case 1 and Case 2 were $70 \mathrm{~m}^{3} \mathrm{~s}-1$ and $35 \mathrm{~m} 3 / \mathrm{s}$ respectively. Sediment was not supplied artificially so the bedload was provided by the flume bed itself during the test.

The water level was observed by using radar type and pressure type of sensors, and the velocity was observed by using Acoustic Doppler Current Profilers (ADCP) and Particle image Velocimetry (PIV). The ADCP transverse observations were made by using transverse round-trips of the observation boat at P410 and P610. The ADCP longitudinal observations were made by using longitudinal round-trips of the observation boat within the sand wave observation section (from P530 to P580).

To observe sand waves, a multi-beam sensor, a direction sensor and a vibration sensor attached to the end of the arm of a power shovel were used. While the power shovel travelled on the shore along the observation section, the sensor moved in the water to measure the three-dimensional shapes of the sand waves. Sand waves observations were made almost once an hour: from $64 \mathrm{~min}$ after the gate opened (herein after the "minute" means the past time after the gate opened.) to $471 \mathrm{~min}$ for Case 1, and from $61 \mathrm{~min}$ to $445 \mathrm{~min}$ for Case 2. Riverbed materials were surveyed at 15 locations randomly in the observation section, and 24 locations on the sand waves. To reduce uncertainties of the measurement caused by the vibration of the power shovel, a GPS sensor was attached together to correct altitudinal positions. The photo and the specification of the multi-beam sensor are shown in Fig. 2 and Table 1, respectively. 

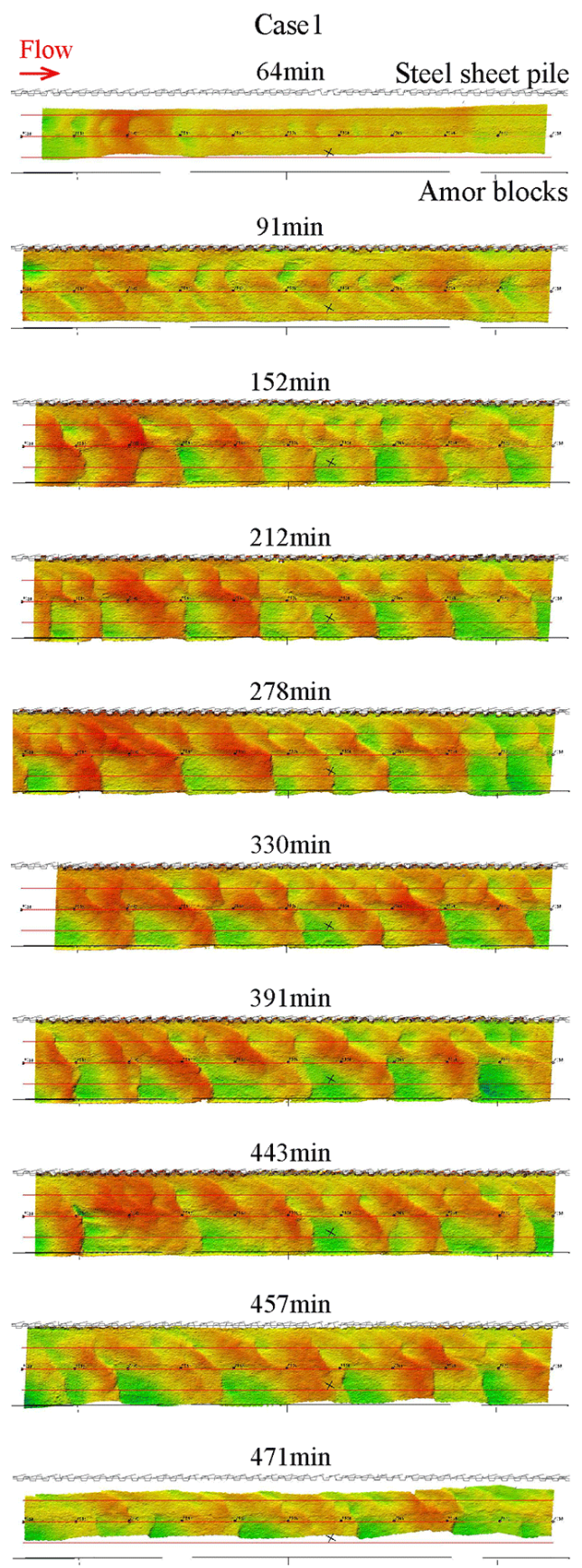

Fig. 3. Contour maps of bed elevation. Left: Case 1, right: Case 2.

\section{Experimental results}

\subsection{Bed configuration}

Figure 3 shows contour maps of bed elevation by the multibeam sensor for Case 1 (left) and Case 2 (right). The legend expresses bed elevation above the sea level. The sensor could measure the whole width of the channel bed for case 1, but could not for Case 2 because the water level was not enough

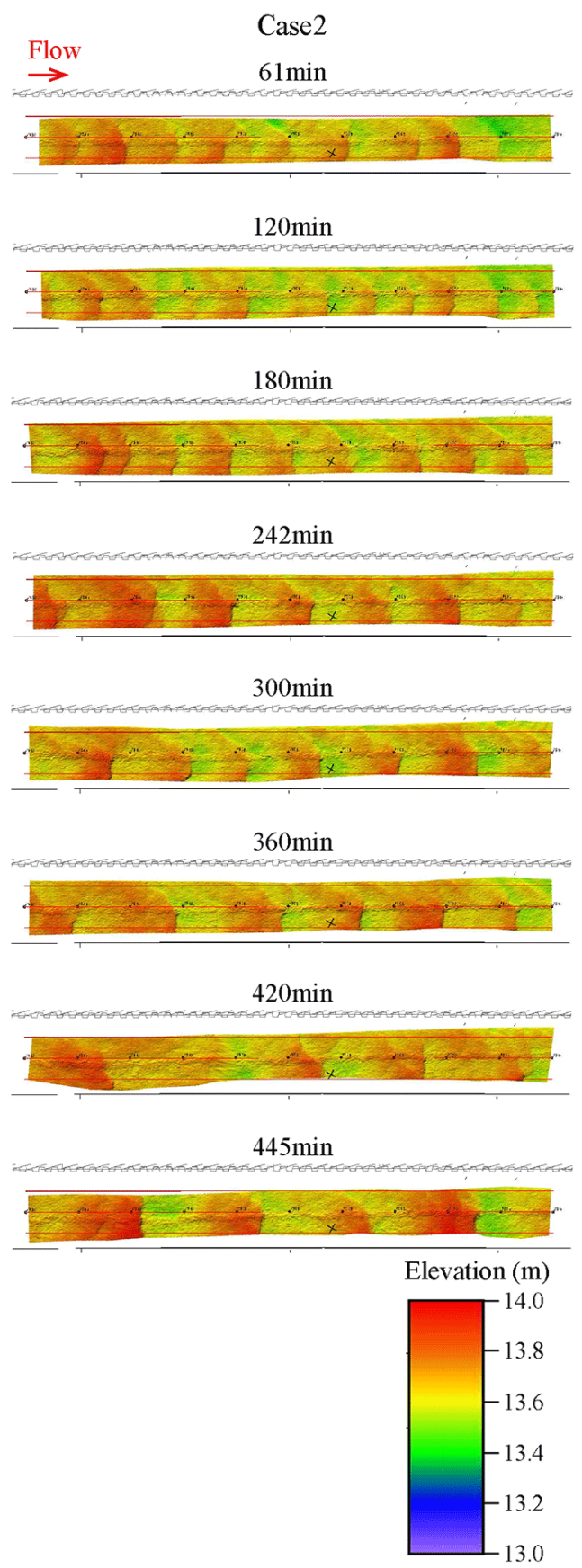

high for the sensor beam to reach the side edges of the channel.

These results confirm that sand waves were generated and developed during both tests. According to the time series of the contour maps for Case 1, the characteristics of the waves are different in the cross-sectional direction. The size of the waves near the pile sheets becomes smaller comparing to those in the centre of the flume. For Case 2, distinct 

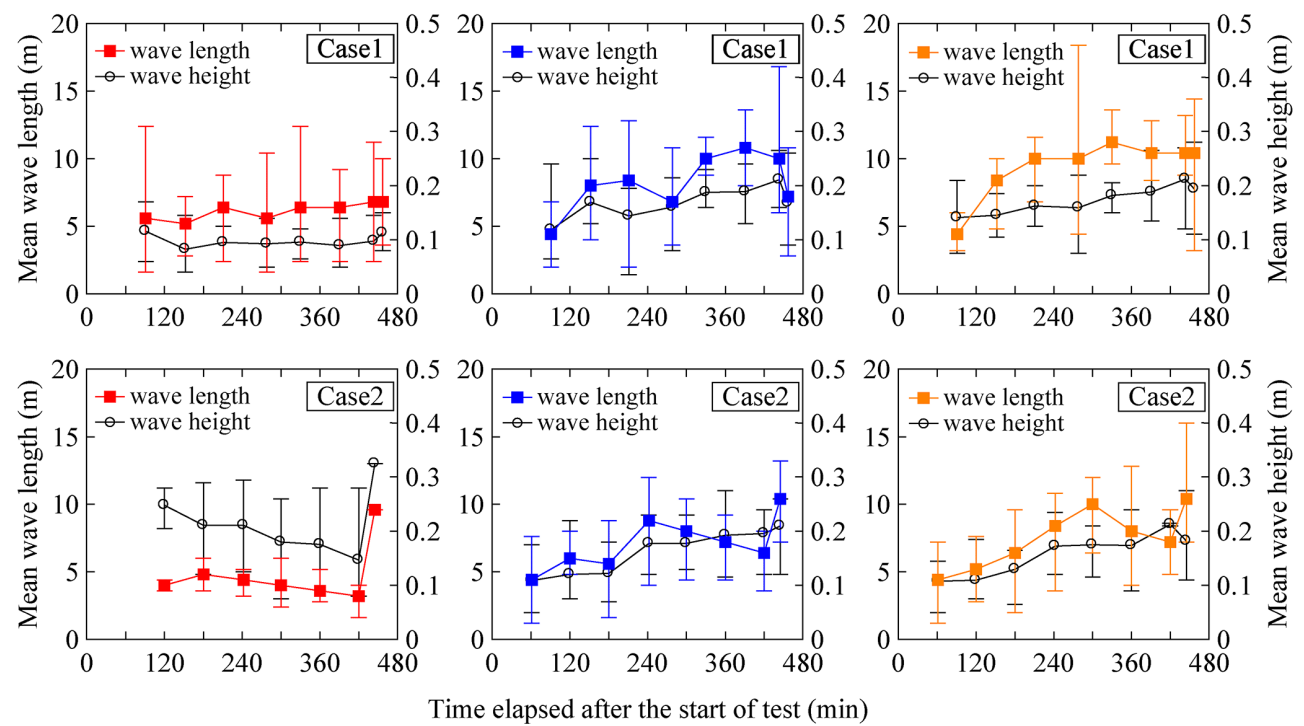

Fig. 4. Time history of sand wave configuration Top: Case 1, bottom: Case 2. Left: line L, centre: line C, right: line R.

Table 1. Specification of multi-beam sensor

\begin{tabular}{ll}
\hline \multicolumn{2}{c}{ Teledyne Reson SEABAT8125 } \\
\hline Frequency & $455 \mathrm{kHz}$ \\
Along-track transmit beamwidth & $1.0^{\circ}$ \\
Across-track receive beamwidth & $0.5^{\circ}$ \\
Number of beams & 240 \\
Max swath angle & $120^{\circ}$ \\
Depth resolution & $6 \mathrm{~mm}$ \\
\hline
\end{tabular}

cross-sectional differences are not seen though the situation near the sheet piles is unknown.

\subsection{Sand waves shapes}

Figure 4 shows the time series of changes in sand waves shapes (i.e., length and height) along survey lines L (left), C (centre) and R (right). The wave length was measured from the trough of the wave to the next trough, and the wave height was measured from the trough to the crest of a wave. The time series of mean values of sand waves shapes along the survey lines $\mathrm{L}, \mathrm{C}$ and $\mathrm{R}$ indicates that the characteristics of sand waves along survey line $\mathrm{L}$ differ from those along the survey lines $\mathrm{C}$ and $\mathrm{R}$. This is attributed to the pile sheet sidewall of the flume, which caused smaller flow velocities than the line $\mathrm{C}$ or $\mathrm{R}$. Because the measurements along the survey line $\mathrm{R}$ were the least influenced by the pile sheet sidewall, the following analysis was made for the data obtained for the survey line $\mathrm{R}$.

Figure 4 (survey line R) shows that the trends of the wave heights and lengths continued to increase. This trend is consistent with the study by Nakagawa and Tsujimoto (1976).
Judging from the changes in wave shapes and roughness in Fig. 4 the sand waves developed at about $152 \mathrm{~min}$ for Case 1 and $120 \mathrm{~min}$ for Case 2. The wave height increased until 330 min for Case 1 and 300 min for Case 2, after which there was little change. According to Suzuki and Michiue (1991), and Miwa and Daido (1991), mixed sand has lower sand waves height than uniform sand. Because this experiment was made using mixed sand, there is the possibility that wave height development was hindered.

\subsection{Hydraulic values}

To discuss relationship between hydraulic resistance and sand waves, hydraulic values in the sand wave observation section are crucial. The observed hydraulic values and the calculated dimensionless shear stress $\tau_{*}$ by Eq. (1) for Case 1 and 2 are shown in Table 2 and 3, respectively.

$\tau_{*}=\frac{h_{m} I}{s d_{m}}$

Where $d_{m}$ is the mean grain size of the bed materials, $s$ is the specific gravity in water of bed materials, $h_{m}$ is the average water depth at each point in time and $I$ is the bed slope. The values of $d_{m}$ and $s$ during the test were substituted by those values measured before and after the test, because $d_{m}$ and $s$ were not measured during the test. $I$ was substituted by the bed slope before the test. Table 2 and 3 also give the mean flow velocity of the sand wave observation section $u_{m}$, which is represented by the averaged velocity obtained by longitudinal ADCP method along the survey line R. Figure 5 shows the result of the longitudinal ADCP observation for Case 1 and Case 2, respectively. 

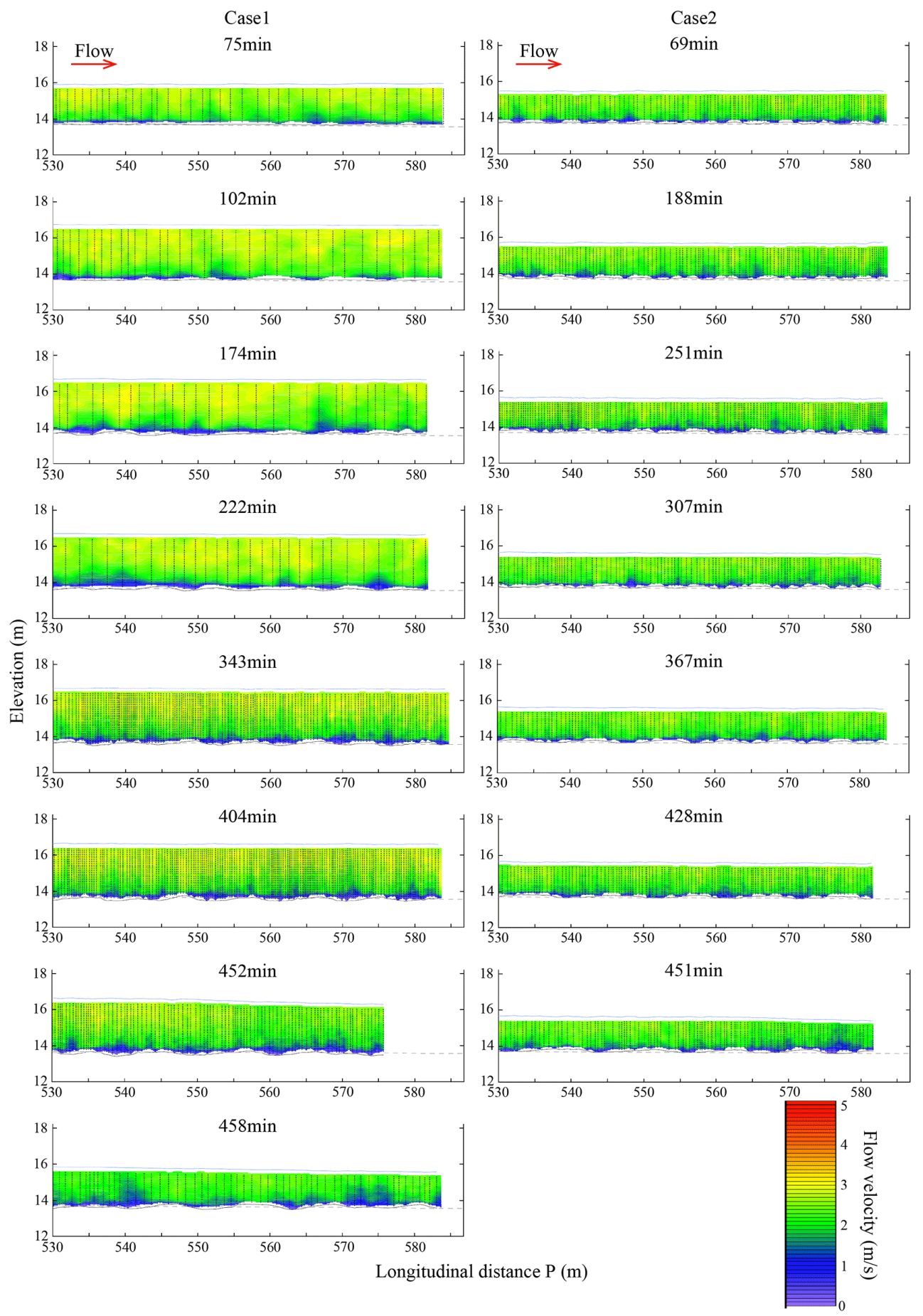

Fig. 5. Velocity distribution observed by longitudinal ADCP measurement. Left: Case 1, Right: Case 2.

\section{Analysis}

\subsection{Manning's roughness coefficient}

Using Manning's Law of Resistance, the temporal changes in the resistance of flume were examined. The values in Table 2 are substituted into Manning's formula (Equation 2) to obtain the roughness at each point in time (Fig. 6). Again, the value of $I$ was substituted by the bed slope before the test.

$n=\frac{1}{u_{m}} h_{m}^{2 / 3} I^{1 / 2}$

Figure 6 shows that the roughness of the both tests increased at the beginning. The increases of the roughness are 
Table 2. Hydraulic values (Case 1).

\begin{tabular}{llllllll}
\hline Time elapsed $(\mathrm{min})$ & $d_{\mathrm{m}}(\mathrm{mm})$ & $s$ & $u_{\mathrm{m}}\left(\mathrm{m} \mathrm{s}^{-1}\right)$ & $h_{\mathrm{m}}(\mathrm{m})$ & $I\left(\times 10^{-3}\right)$ & $\tau_{*}\left[d_{\mathrm{m}}=10.4\right]$ & $\tau_{*}\left[d_{\mathrm{m}}=17.6\right]$ \\
\hline Before test & 10.4 & 1.60 & - & - & 1.63 & - & - \\
91 & - & - & 2.51 & 2.75 & - & 0.269 & 0.157 \\
152 & - & - & 2.42 & 2.96 & - & 0.290 & 0.169 \\
212 & - & - & 2.40 & 2.96 & - & 0.289 & 0.169 \\
278 & - & - & 2.42 & 2.92 & - & 0.286 & 0.167 \\
330 & - & - & 2.38 & 2.91 & - & 0.285 & 0.166 \\
391 & - & - & 2.36 & 2.94 & - & 0.288 & 0.168 \\
443 & - & - & 2.22 & 2.92 & - & 0.286 & 0.167 \\
After test & 17.6 & 1.62 & - & - & 1.43 & - & - \\
\hline
\end{tabular}

Table 3. Hydraulic values (Case 2).

\begin{tabular}{|c|c|c|c|c|c|c|c|}
\hline Time elapsed (min) & $d_{\mathrm{m}}(\mathrm{mm})$ & $s$ & $u_{\mathrm{m}}\left(\mathrm{ms}^{-1}\right)$ & $h_{\mathrm{m}}(\mathrm{m})$ & $I\left(\times 10^{-3}\right)$ & $\tau_{*}\left[\mathrm{~d}_{m}=15.8\right]$ & $\tau_{*}\left[\mathrm{~d}_{m}=15.4\right]$ \\
\hline Before test & 15.8 & 1.63 & - & - & 2.13 & - & - \\
\hline 61 & - & - & 2.19 & 1.78 & - & 0.134 & 0.138 \\
\hline 120 & - & - & 2.20 & 1.88 & - & 0.153 & 0.158 \\
\hline 180 & - & - & 2.24 & 1.94 & - & 0.162 & 0.167 \\
\hline 242 & - & - & 2.18 & 1.89 & - & 0.153 & 0.157 \\
\hline 300 & - & - & 2.20 & 1.88 & - & 0.155 & 0.160 \\
\hline 360 & - & - & 2.17 & 1.88 & - & 0.153 & 0.158 \\
\hline 420 & - & - & 2.18 & 1.89 & - & 0.153 & 0.158 \\
\hline 445 & & & 2.08 & 1.88 & - & 0.153 & 0.158 \\
\hline After test & 15.4 & 1.63 & - & - & 1.93 & - & - \\
\hline
\end{tabular}

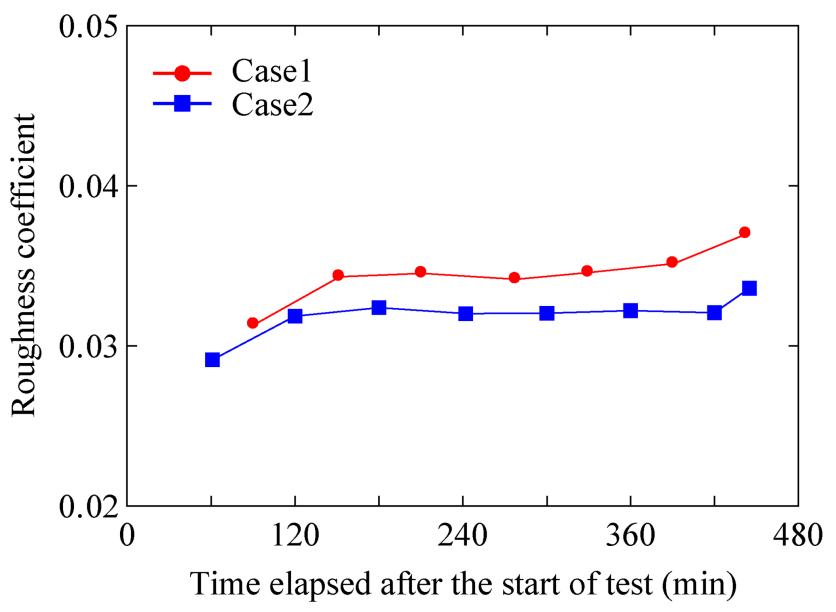

Fig. 6. Time history of Manning's roughness coefficient.

considered to be attributed to the increases in the wave length and height. The increases in wave length and height alone cannot explain the increase in the roughness near the ending. Other causes, such as an increase in grain size, may be attributable to the roughness increase; however, this has yet to be confirmed.

\subsection{Vertical velocity distribution}

In the experiment, under full-scale movable riverbed conditions, whose scale is close to that of an actual river, the vertical flow velocity distribution above the sand waves was observed. Then, examinations were made on the approximation with the logarithmic distribution.

Figure 7 shows the vertical flow velocities at the three locations between a trough and another trough of the representative wave at the timing of 102 minutes and 290 minutes of Case 1. Figure 7 also shows the longitudinal bed elevation measured by ADCP and the authors applied for Eq. (3) to calculate logarithmic flow velocity distributions. The calculations were made using mean grain sizes before the test.

$u=u_{*}\left\{8.5+5.75 \log \left(\frac{y}{2 d_{m}}\right)\right\}$

Where, $y$ is the height from the riverbed, $u$ is the flow velocity at a height of $y$ above the bed, and $u_{*}$ is the friction velocity.

At 102 min when the sand waves had not fully developed, the observed distributions follow the logarithmic distributions. This indicates that the form drag had not produced yet. At $290 \mathrm{~min}$, the observed at troughs confirm that there are reductions in flow velocity near the bottom which are considered due to form drag while the observed around the top 

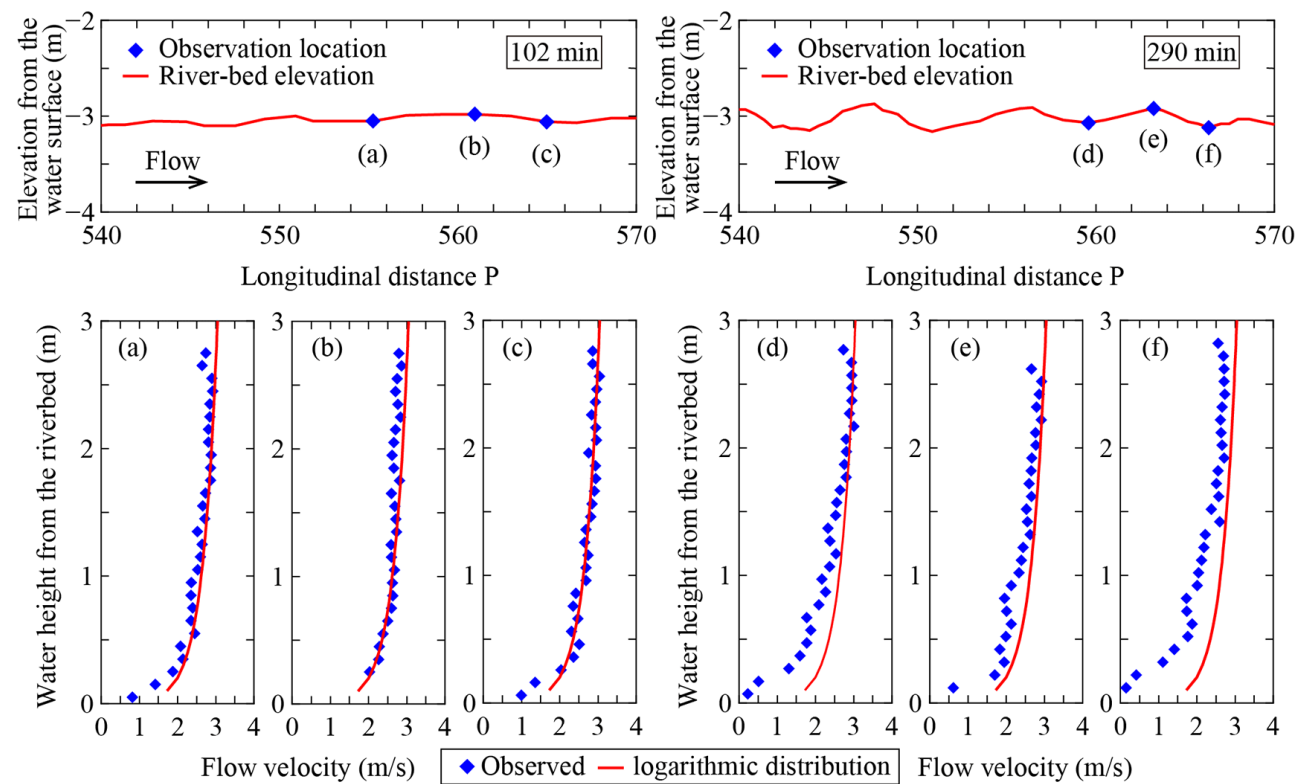

Fig. 7. Vertical velocity observed on the sand waves and logarithmic distribution (Case 1).

of the crest roughly agree with the logarithmic curve as was reported by Miwa and Daido (2011). Accordingly, the logarithmic flow velocity distribution assumed for the estimation of effective shear force was verified by the full-scale movable bed experiment.

\section{Conclusions}

The authors conducted a full-scale movable bed experiment at the Chiyoda Experimental Flume on the Tokachi River, and successfully measured sand waves by multi-beam sensors during the flow of water.

Based on the time history of the sand wave shapes, the authors summarized the characteristics of the sand waves and clarified that the wave shapes, wave length and wave height, were fully developed except near the vertical steel-pile wall.

Manning's roughness coefficient was calculated for both cases, and the authors found that these values jumped up when the sand waves developed, which indicated that the form drag was observed in the experiment.

The logarithmic flow velocity distribution that was assumed for calculation of the effective shear force (friction drag) was verified by the full-scale movable bed experiment.

\section{References}

Engelund, F.: Hydraulic Resistance of Alluvial Streams. Journal of the Hydraulics Division, ASCE, Proc. ASCE, 92, 315-326, 1966.

Kishi, C. and Kuroki, M.: Bed Forms and Resistance to Flow in Erodible-Bed Channels (I), Bull. Fac. Eng., No. 67, Hokkaido University, Japan, 1973.

Kikkawa, H. and Ishikawa, T.: Hydraulic Resistance of Streams over Dunes and Ripples. Proc. JSCE, 281, 55-63, 1979.

Nakagawa, H. and Tsujimoto, T.: Experimental Study on Evolution of Sand Waves from an Initially Flattened Bed, Disaster Prevention Research Institute Annals, 19, 289-309, 1976.

Miwa, H. and Daido, A.: Mechanism of Flow Resistance in Alluvial Streams with Sand Waves and Prediction of Sediment Transport System, Proc. Hydr. Eng., 55, S758-S762, 2011.

Miwa, H. and Daido, A.: Experimental Study on Interaction between the Sorting of Sand Mixtures and The Development of Sand Waves. Proc. Hydr. Eng., 35, 403-410, 1991.

Shimada, T., Kakinuma, T. and Miyake, H.: Analysis of Mechanisms of Bank Failure and Channel Widening due to Wave Overtopping in the Chiyoda Experimental Flume. Hokkaido Development Technology Conference, 2011.

Suzuki, K. and Michiue, M.: On the Dune Height and the Influence of Sand Mixture on Its Characteristics. Proc. Jpn. Conf. Hydr., 23, 151-156, 1979.

Takemoto, M., Takagi, J., Makino, N., Morita, Y.: The Second Report on Flood Observation at the Lower Reaches of the Ishikari River. Survey, Experiment and Research Report on Rivers, Civil Engineering Research Institute, 1982.

Task Committee on the Bed Configuration and Hydraulic Resistance of Alluvial Streams, Committee on Hydraulics and Hydraulic Engineering, JSCE: The Bed Configuration and Roughness of Alluvial Streams. Proc. JSCE, 210, 65-91, 1973.

Yalin, M. S. and Karahan, E.: Steepness of Sedimentary Dunes, J. Hydr. Div., ASCE, 105, 381-392, 1979. 